\title{
Humanidades como Disciplina da Graduação em Medicina
}

\author{
Humanities as a Discipline in the \\ Undergraduate Medical Course
}

José Ricardo de Carvalho Mesquita Ayres ${ }^{I}$

Izabel Cristina Rios ${ }^{1}$

Lilia Blima Schraiber

Marcia Thereza Couto Falcão

André Motal

\author{
PALAVRAS-CHAVE: \\ - Humanidades Médicas; \\ - Humanização da Assistência; \\ - Educação Médica.
}

\section{KEYWORDS:}

- Medical Humanities;

- Humanization of Assistance;

- Medical Education.

\section{RESUMO}

Apresenta-se o desenvolvimento de uma disciplina em Humanidades Médicas. Objetivou-se examinar contribuições conceituais e práticas do conhecimento humanístico tendo por base o cuidado em saúde. A disciplina foi estruturada em quatro módulos inter-relacionados, correspondentes a áreas particulares do conhecimento humanístico: Filosofia, História, Socioantropologia e Psicodinâmica do Encontro Clínico. São apresentadas as diferentes estratégias didático-pedagógicas utilizadas, os conteúdos programáticos particulares a cada módulo e suas inter-relações, e os impactos produzidos nos alunos, nos próprios docentes e no desenho disciplinar. O exame dessa experiência mostrou que a disciplina conseguiu desenvolver tanto as particularidades quanto a integração entre os módulos, segundo a percepção dos docentes e alunos. Depois da primeira turma, houve reformulação de temas de aulas e metodologias, mas se reafirmou a estratégia modular e a escolha de pesquisadores especializados nos conteúdos particulares como equipe docente, permitindo ganhos de conhecimentos relativos à conceituação do cuidado do ponto de vista da integralidade em saúde. Conclui-se que o desenho da disciplina se mostrou adequado aos objetivos educacionais propostos, reforçando a relevância das Humanidades para o currículo da escola médica.

\begin{abstract}
This paper presents the development of an academic discipline in Medical Humanities. The goal was to analyse both practical and conceptual contributions from humanistic knowledge toward health care. The discipline was organised in four inter-related modules corresponding to particular areas of humanistic knowledge: philosophy, history, socio-anthropology and the psychodynamics of a medical consultation. The text points out the different pedagogic and didactic strategies used, the programmatic content of each module and their bridge-overs, and the impacts on students, lecturers and the actual design of the discipline. The discipline, according to the opinion of lecturers and students, was found to be capable of developing not only specific content but also interrelated content between modules. After the first class had completed the course, some themes and methods were reformulated, but the After the first time, some reorientation of themes and methods were done, but the modular strategy and the choice of specialized researchers as the teacher team were reaffirmed, leading to improvements on knowledge about the concept of health care since a comprehensive perspective in health. The conclusion is that the discipline's design suited the proposed educational goals and reinforces the relevance of humanities to the medical school curricula
\end{abstract}

ABSTRACT 


\section{INTRODUÇÃO}

As Humanidades entraram no cenário do ensino médico há vários anos, constituindo a área das Humanidades Médicas ${ }^{1,2}$. Afirmam-se como axiais no desenvolvimento da boa prática em Medicina, ao propiciarem maior compreensão das expressões do sofrimento humano e das manifestações socioculturais dos adoecimentos, assim como de habilidades de comunicação e construção de vínculos que possibilitam a interação necessária a qualquer ato médico. Não menos importantes são as aproximações com a Filosofia e a Ética, não só como exercício reflexivo do pensar, mas como método para a tomada de decisão clínica e assistencial, momento nuclear da prática médica.

As Humanidades Médicas aparecem nos currículos como ferramentas para a prática e como formação mais global, na qual se engendra a identidade profissional ${ }^{3}$, ainda que a formação humanística do aluno envolva, adicionalmente, a articulação dos temas dessa área com vários outros cenários da aprendizagem. Considera-se que durante a graduação essa formação deva decorrer do trabalho conjunto entre as diversas disciplinas específicas de Humanidades, da discussão de temas humanísticos nas disciplinas clínicas e da experiência cotidiana de cultura institucional que dissemine valores humanistas ${ }^{4}$.

Nos anos 1980, disciplinas nessa área figuravam como optativas. Hoje, é frequente sua inserção nos currículos obrigatórios, principalmente as que tratam de Ética e habilidades comunicacionais ${ }^{5,6}$. Apesar de seu crescimento, são comuns depoimentos sobre a resistência de alunos e professores mais identificados com o núcleo tecnicista da Medicina ${ }^{7,4}$. Não obstante, visando formar médicos mais competentes para a sociedade, várias escolas têm buscado o aprimoramento didático-pedagógico, e o debate atual sobre o ensino das Humanidades Médicas não se atém à sua pertinência ou não, mas ao desenvolvimento de projetos pedagógicos adequados aos seus objetivos educacionais ${ }^{8,9}$.

Ademais, a formação humanística em Medicina ganha relevo no cenário nacional, para a efetivação do Sistema Único de Saúde. Destaca-se o desenvolvimento de competências e habilidades relacionadas à prática médica geral e voltada para todos os níveis de atenção, bem como para a apreensão da dimensão individual e coletiva do cuidado em saúde, como consta das diretrizes curriculares atuais ${ }^{10}$.

Alguns projetos de orientação para mudança curricular expressam essa intenção governamental, como o Programa Nacional de Reorientação da Formação Profissional em Saúde (Pró-Saúde) ${ }^{11}$ e o Programa de Educação pelo Trabalho para a Saúde - PET-Saúde ${ }^{12}$. O tema é também pauta em fóruns voltados à educação médica em diferentes escolas.
A Faculdade de Medicina da Universidade de São Paulo ${ }^{14}$, respondendo às discussões internas quanto ao perfil profissional desejado, construiu novos cursos e estágios curriculares sobre as Humanidades, tendo introduzido no currículo obrigatório, desde 1998, disciplinas nesse sentido. Em 2009, após várias reformulações nessa área, foi estabelecida uma disciplina introdutória denominada Medicina e Humanidades, ministrada para o primeiro ano de graduação e cujo processo de formulação e desenvolvimento até a presente data constituiu a base empírica de nossas presentes reflexões.

\section{O PLANEJAMENTO PEDAGÓGICO: CRIAÇÃO INTERDISCIPLINAR}

A disciplina contou desde seu primeiro momento com coordenador e docentes de formação interdisciplinar, sempre aliando Medicina e Saúde com o campo das Humanidades. Além disso, neste último campo, contou-se com docentes de formação específica diversa: Sociologia, Antropologia, História, Psicologia e Filosofia.

Por cerca de seis meses, um grupo de cinco docentes se reuniu semanalmente para formular a disciplina. Valendo-se do planejamento pedagógico da integração curricular ${ }^{15}$, definiram-se: as necessidades educacionais do aluno de primeiro ano de Medicina para o início da formação humanística; os objetivos decorrentes dessas necessidades; os conteúdos pertinentes; a organização de tais conteúdos; as estratégias educacionais; os métodos de ensino e de avaliação; a comunicação dentro do processo e a gestão do processo como um todo.

Considerando que o exercício da medicina requer domínios provenientes das disciplinas biomédicas e clínicas, assim como os da formação humanística, tomou-se como eixo estruturador da disciplina a discussão conceitual e aplicada do "cuidado"15, entendido como a busca de articulação, no cotidiano da atenção em saúde, entre o adequado uso dos recursos tecnocientíficos da biomedicina (êxito técnico) e a construção de respostas efetivas aos legítimos interesses e valores dos indivíduos e grupos populacionais assistidos (sucesso prático). Com base nessa perspectiva, definiu-se como objetivo geral da disciplina capacitar o aluno a reconhecer os pressupostos e requisitos do cuidado em saúde. O referencial subjacente, portanto, foi o de que, nessa condição de campo articulado aos objetivos educacionais das próprias bases biomédicas e clínicas da Medicina, as Humanidades Médicas fariam sentido para o aluno.

A nova disciplina iria, então, apresentar as contribuições das diversas áreas de conhecimento humanístico para o desenvolvimento do cuidado em saúde, no momento tanto de diagnóstico (individual ou coletivo), quanto de intervenção e acompanhamento das ações de prevenção, tratamento e/ou reabilitação. 
De acordo com as qualificações do corpo docente, foram delimitados quatro núcleos de conhecimento, estruturados em quatro módulos sequenciais inter-relacionados: (1) bases filosóficas do conhecimento científico e das práticas em medicina e saúde; (2) história das práticas assistenciais em medicina e saúde pública; (3) aspectos socioantropológicos do processo saúde-doença; (4) relações psicodinâmicas nas práticas em saúde.

Articulados ao eixo transversal do ensino do cuidado, buscaram-se os objetivos específicos de desenvolver no aluno: (a) compreensão do significado e implicações práticas do cuidado como norteador técnico e ético da prática médica; (b) compreensão da natureza da contribuição das Humanidades para a formação e atuação profissionais; (c) conhecimento de um conjunto básico de conceitos e métodos da Filosofia, da História, Da Sociologia, da Antropologia e da Psicologia, tornando-se capaz de relacioná-los a situações cotidianas de atenção à saúde; (d) o interesse para com as atitudes e habilidades de respeito à diversidade humana e de atenção ao outro; (e) reflexão sobre os desafios técnicos e éticos do cuidado da saúde de indivíduos e grupos humanos.

Esses objetivos gerais foram traduzidos para cada um dos módulos. Buscou-se realizá-los em conteúdos programáticos que, segundo os quadros teóricos adotados em cada módulo, levaram a alguns conceitos-chave, sempre relacionados ao tema do cuidado. Do ponto de vista metodológico, o processo educacional valeu-se de aulas expositivas e metodologias ativas, tais como trabalhos de campo e discussão em pequenos grupos. A disciplina produziu também formas próprias de avaliação em três sentidos: dos alunos, dos docentes e do processo. Todo esse desenho é apresentado no Quadro 1.

\section{REFLEXÕES SOBRE A DISCIPLINA: EXAME DO PROCESSO DE DESENVOLVIMENTO DAS ATIVIDADES DE ENSINO}

A disciplina foi implantada em 2010, no segundo semestre do currículo obrigatório, com quatro horas-aula semanais, por quatro meses, permanecendo assim até o momento. Os 180 alunos são divididos em duas turmas e cada qual em três subgrupos. As aulas expositivas são ministradas para todos os alunos e conduzidas a cada módulo pelo docente que possui a formação específica relativa ao módulo em questão. Essas aulas são sempre acompanhadas pelos demais, que registram as atividades, o que é utilizado como informação para as reuniões semanais de monitoramento do processo.

Já as atividades em pequenos grupos são sempre conduzidas pelo mesmo docente ao longo da disciplina, vinculando-se, assim, cada grupo ao seu docente. Desta forma, todos os docentes participam de todas as atividades em pequenos grupos, independentemente de sua qualificação especializada ou do módulo em curso. A disciplina conta com monitores, constituídos, na primeira turma, de estagiários provenientes do corpo discente da pós-graduação e, a partir da segunda turma, também provenientes de egressos da disciplina: alguns dos alunos do segundo ano de graduação.

As aulas expositivas seguem o padrão clássico, buscando sempre apresentar situações práticas exemplares em que os conteúdos a serem ministrados fiquem claros, trabalhando de forma concisa os conceitos-chave. Sua duração não ultrapassa 60 minutos. Nos pequenos grupos, são adotadas metodologias ativas, previamente preparadas em reuniões docentes semanais.

Atenção particular tem sido dada ao monitoramento do processo como um todo. Um de seus recursos são as reuniões semanais do corpo docente e dos monitores. Nestas reuniões, são debatidas as informações provenientes dos registros de cada docente quanto às aulas expositivas e das observações dos mesmos quanto às atividades em pequenos grupos. Igualmente, são apresentadas as observações dos monitores. Estes também possuem outro espaço de reunião, mais voltado ao próprio aperfeiçoamento da monitoria, mas que também é usado como momento de apresentação e discussão do desenvolvimento da disciplina, pelo olhar do monitor.

Em particular na primeira turma, o monitoramento do desenvolvimento da disciplina também contou com registros de observador externo, na modalidade de caderno de campo em observação do tipo etnográfica. Este recurso foi muito importante para readequações do desenho da disciplina.

Após a realização da primeira turma, foram processadas mudanças que reorientaram temas eleitos para o trabalho do conteúdo programático e/ou as estratégias didático-pedagógicas. Assim, o conteúdo permanece o mesmo, mas registraram-se mudanças em todos os módulos, sendo as maiores registradas nos módulos de Filosofia e de História. Também se identificou a necessidade de diversificar as metodologias ativas operadas nos pequenos grupos ao longo da disciplina. Estas envolvem a problematização na discussão de casos e discussão de produtos de atividades de campo, além de vídeos e filmes. A cada módulo, portanto, busca-se usar metodologia diversa dos demais.

Fundamental para o aprimoramento da disciplina ${ }^{16,17}$, buscam-se avaliações ancoradas em diversas metodologias, propiciando múltiplos olhares e discursos e dando voz aos diferentes sujeitos envolvidos.

Os alunos são avaliados quanto a: grau de apreensão dos conceitos-chave; capacidade de elaboração crítica e aplicação prática dos conteúdos trabalhados; e desenvolvimento de atitudes de compromisso individual e engajamento coletivo. 
QUADRO 1

Desenho geral da disciplina Medicina e Humanidades

\begin{tabular}{|c|c|c|c|c|}
\hline Módulo & $\begin{array}{l}\text { I. Aspectos filosóficos do } \\
\text { cuidado em saúde }\end{array}$ & $\begin{array}{l}\text { II. Aspectos históricos } \\
\text { do cuidado em saúde }\end{array}$ & $\begin{array}{l}\text { III. Aspectos } \\
\text { socioantropológicos do } \\
\text { cuidado em saúde }\end{array}$ & $\begin{array}{l}\text { IV. Aspectos psicodinâmicos do } \\
\text { cuidado em saúde }\end{array}$ \\
\hline Objetivo específico & $\begin{array}{l}\text { Conceituar cuidado, } \\
\text { trabalhando a base } \\
\text { científica e o sentido } \\
\text { prático das ações de } \\
\text { atenção à saúde de } \\
\text { indivíduos e grupos } \\
\text { humanos. }\end{array}$ & $\begin{array}{l}\text { Conceituar a } \\
\text { historicidade das } \\
\text { práticas de saúde, } \\
\text { trabalhando } \\
\text { as mudanças e } \\
\text { permanências } \\
\text { históricas da prática } \\
\text { médica com ênfase na } \\
\text { modernidade. }\end{array}$ & $\begin{array}{l}\text { Conceituar as bases sociais e } \\
\text { culturais do adoecimento e } \\
\text { do cuidado, trabalhando as } \\
\text { implicações de classe social, } \\
\text { raça, gênero, religião e } \\
\text { crenças/valores na saúde. }\end{array}$ & $\begin{array}{l}\text { Conceituar encontro clínico e } \\
\text { as bases psicodinâmicase éticas } \\
\text { da relação médico-paciente, } \\
\text { trabalhando habilidades } \\
\text { comunicacio- } \\
\text { nais e aspectos relacionais da prática } \\
\text { médica. }\end{array}$ \\
\hline $\begin{array}{l}\text { Conteúdo } \\
\text { programático }\end{array}$ & $\begin{array}{l}\text { 1. Da ontologia existencial } \\
\text { às práticas de saúde: a } \\
\text { questão do cuidado; } \\
\text { 2. Êxito técnico e sucesso } \\
\text { prático como constituintes } \\
\text { do cuidado; } \\
\text { 3.Intersubjetividade } \\
\text { no cuidado: projeto de } \\
\text { felicidade e orientação } \\
\text { prática da intervenção } \\
\text { assistencial; } \\
\text { 4. Acolhimento, escuta e } \\
\text { responsabilida- de como } \\
\text { requisitos para o cuidado; } \\
\text { 5.Racionalidade técnica } \\
\text { e racionalidade científica } \\
\text { na medicina: bases } \\
\text { epistemológicas dos } \\
\text { saberes e tecnologias } \\
\text { médicas. }\end{array}$ & $\begin{array}{l}\text { 1. História, } \\
\text { historiografia e } \\
\text { memória; } \\
\text { 2.Historicida-de } \\
\text { das práticas sociais } \\
\text { e da medicina como } \\
\text { prática social (saber } \\
\text { e intervenção): } \\
\text { abordagens históricas } \\
\text { do corpo, do indivíduo } \\
\text { e das técnicas; } \\
\text { 3. Mudanças históricas } \\
\text { na identidade social de } \\
\text { médico; } \\
\text { 4.Circularida-de, } \\
\text { permanências e } \\
\text { rupturas na história das } \\
\text { práticas de saúde; } \\
\text { 5.Instituições, } \\
\text { instituídos, instituintes } \\
\text { e institucionalização da } \\
\text { medicina brasileira. }\end{array}$ & $\begin{array}{l}\text { 1.Significa-dos sócio- } \\
\text { culturais da saúde, } \\
\text { adoecimentoe cuidado: } \\
\text { os conceitos de doença ( } \\
\text { disease) e enfermidade } \\
\text { ( ilness); morte social; } \\
\text { itinerários terapêuticos; } \\
\text { saber médico e saber } \\
\text { popular } \\
\text { 2. Religiosi-dade, } \\
\text { espiritualidade e práticas } \\
\text { religiosas diante do processo } \\
\text { de adoecimento } \\
\text { 3. Gênero e saúde: } \\
\text { diferenciais de adoecimento } \\
\text { e cuidado entre homens e } \\
\text { mulheres } \\
\text { 4. Diferen-ciais de Classe } \\
\text { social, raça e etnia na } \\
\text { produção de vulnerabi } \\
\text { lidades em saúde }\end{array}$ & $\begin{array}{l}\text { 1. Intersubje-tividade como } \\
\text { comunicação } \\
\text { 2.Conceitos de psicodinâmica } \\
\text { na prática médica: empatia, } \\
\text { transferência, identificação } \\
\text { 3. Ética das relações: alteridade, } \\
\text { respeito e responsabili-dade na } \\
\text { dinâmica entre o "eu" médico e o } \\
\text { "outro" paciente } \\
\text { 4. Humani-dades e cuidado: } \\
\text { aspectos históricos e ético-políticos } \\
\text { da humanização na formação e no } \\
\text { sistema de saúde }\end{array}$ \\
\hline $\begin{array}{l}\text { Métodos di-dáticos e } \\
\text { pedagógi-cos }\end{array}$ & $\begin{array}{l}\text { Aulas teórico- } \\
\text { expositivas com } \\
\text { recursos audiovisuais; } \\
\text { apresentação de vídeos e } \\
\text { discussões em pequenos } \\
\text { grupos de casos clínicos e } \\
\text { artigos. }\end{array}$ & $\begin{array}{l}\text { Aulas teórico- } \\
\text { expositivas com } \\
\text { recursos audiovisuais; } \\
\text { discussões em } \\
\text { pequenos grupos de } \\
\text { documentos históricos } \\
\text { e histórias de vida de } \\
\text { médicos; } \\
\text { visitas a instituições } \\
\text { e/ou entrevistas com } \\
\text { profissionais. }\end{array}$ & $\begin{array}{l}\text { Aulas teórico-expositivas } \\
\text { com recursos audiovisuais; } \\
\text { apresentação de vídeos e } \\
\text { discussões em pequenos } \\
\text { grupos de itinerários } \\
\text { terapêuticose observações } \\
\text { de estudos etnográficos. }\end{array}$ & $\begin{array}{l}\text { Aulas teórico-expositivas com } \\
\text { recursos audiovisuais; } \\
\text { discussões em pequenos grupos de } \\
\text { casos clínicos, exercício de medicina } \\
\text { e narrativa e dramatizações do } \\
\text { encontro clínico; } \\
\text { discussão do trabalho de campo: } \\
\text { entrevistas com pacientes. }\end{array}$ \\
\hline $\begin{array}{l}\text { Avaliação final do } \\
\text { módulo }\end{array}$ & \multicolumn{2}{|c|}{$\begin{array}{l}\text { Elaboração de pôster, com imagem e texto sobre } \\
\text { "cuidado", escolha da imagem livre; texto baseado } \\
\text { nos módulos de Filosofia e História. }\end{array}$} & $\begin{array}{l}\text { Trabalho dissertativo sobre } \\
\text { casos vistos em disciplina } \\
\text { prévia - Atenção Primária I. }\end{array}$ & $\begin{array}{l}\text { Entrevistas com pacientes em } \\
\text { diferentes contextos de assistência. }\end{array}$ \\
\hline
\end{tabular}


Para tanto, são solicitados trabalhos de conclusão de cada módulo, prova final dissertativa com quatro situações-problema referentes aos módulos e registros dos docentes sobre a conduta dos alunos nos pequenos grupos (apreciando respeito aos colegas, interesse e participação).

Sessões de devolutivas das avaliações são realizadas, conforme a necessidade, no meio e no final da disciplina ou apenas em seu final. Na primeira turma, foram necessárias as duas devolutivas, o que não ocorreu nas demais turmas. Isto porque, após o trabalho apresentado pelos alunos no término do primeiro módulo, observou-se a baixa qualidade dos trabalhos, com baixo rendimento do aprendizado, indicando pouco comprometimento dos alunos com uma disciplina da área de Humanidades. Essa intervenção precoce no transcurso da disciplina se mostrou fundamental à implantação da mesma, pois permitiu o debate aberto acerca da relevância das Humanidades e da competência científica e prática de seus conteúdos frente à Medicina. Nas turmas subsequentes, essa questão foi aprofundada nas próprias aulas expositivas a fim de tornar bem clara a contribuição das Humanidades para a prática do médico no sentido do bom cuidado.

Decorridos já três anos de desenvolvimento da disciplina, cremos ter diminuído a força da representação usual das Humanidades pelo alunado como uma disciplina "menor" que as do conhecimento biomédico e clínico. Este aspecto foi um dos pontos críticos que se tinha em mente desde o planejamento da disciplina. Para lidar com ele, adotou-se, e ainda se adota, a perspectiva de valorizar as diferenças conceitual, metodológica e prática entre as Humanidades e o conhecimento biomédico ou clínico, desconstruindo-se, contudo, a desigualdade hierárquica entre os campos disciplinares.

Foi nesse exato sentido que, ao se compor a equipe de trabalho, optou-se por contar com "especialistas" ou docentes bem formados na pesquisa e no conhecimento próprio a distintos ramos das Ciências Humanas e Sociais e da Filosofia. Este ponto de partida correspondeu à intenção de ultrapassar a visão de que conhecimentos nesses ramos não requereriam formação específica, pois se reduziriam ao senso comum acerca da vida em sociedade.

A proposta de desconstrução dessa representação tem residido em sistematicamente fazer diferir os conhecimentos utilizados na disciplina e que efetivamente tratam de aspectos distintos da vida em sociedade, das elaborações do cotidiano, tais como as opiniões sobre acontecimentos sociais, o que tem sido feito apontando-se a qualidade densa de formulação dos diversos conceitos trabalhados, enquanto explicações acerca do humano-social. Outro recurso pedagógico na mesma direção tem sido a constante vinculação dos conceitos a elementos da prática profissional, buscando-se demonstrar que existem impactos práticos quando o profissional se apropria desses conceitos e que eles tornam a prática mais exitosa, tanto na dimensão relacional, quanto no acerto da intervenção técnico-científica.

Três pontos de inflexão no curso merecem destaque por evidenciarem a influência dessa proposta pedagógica no comportamento dos alunos, o que usamos como indicador da desconstrução em curso acerca da baixa valorização dos conhecimentos humanísticos frente aos de cunho clínico.

$\mathrm{O}$ primeiro tem sido a realização pelos alunos de trabalho sobre o eixo integrador da disciplina: o cuidado em medicina. Esta atividade, que no primeiro ano de realização da disciplina correspondeu ao trabalho final do módulo de Filosofia e atualmente inclui os módulos de Filosofia e História em conjunto, tem se mostrado bastante central para o bom curso da disciplina ao constituir, já em sua metade, uma oportunidade para a discussão do domínio dos conceitos novos e da articulação da base humanística de conhecimento à medicina enquanto contribuição científica à prática central do médico: o encontro clínico. Os melhores trabalhos são publicados em pôsteres expostos na Faculdade de Medicina em local de grande circulação de alunos e em especial de professores. A Figura 1 apresenta um deles.

FigURA 1

Pôster produzido por aluna na disciplina Medicina e Humanidades (FMUSP, 2010)

\section{Novas Rotas para o Cuidado}

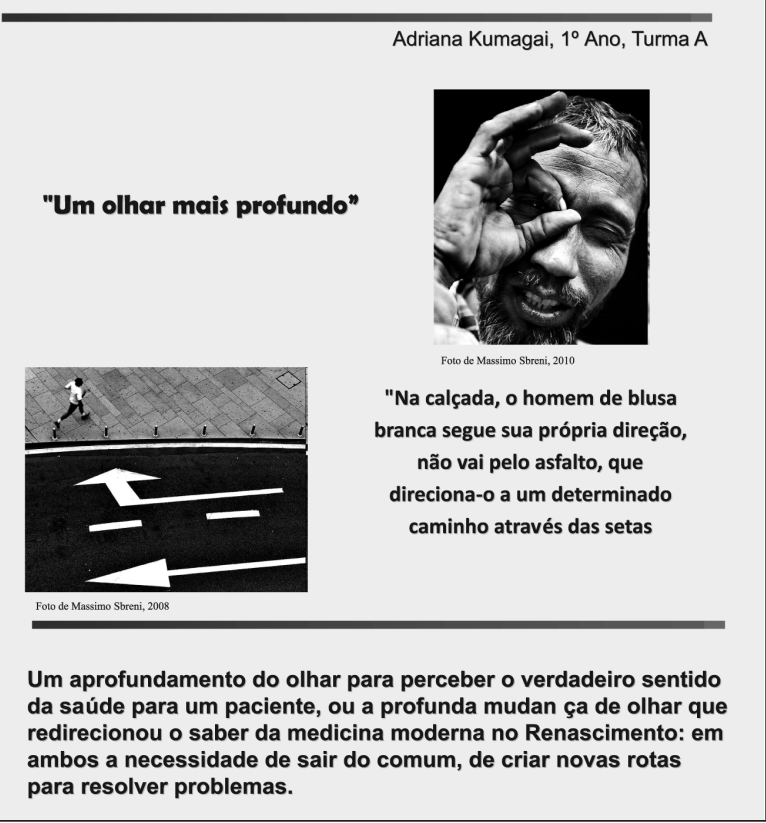


A confecção desse trabalho no primeiro ano de realização da disciplina demonstrou a grande dificuldade dos alunos em lidar conceitualmente com a noção de "cuidado", tendendo a tomá-la pelas representações de senso comum acerca da prática médica. Nestas, cuidar é ação remetida à tradição filantrópica da medicina de cunho caritativo e paternalista, com o que o cuidado se reduz ou a uma simpatia pessoal do médico pelo doente ou a demonstrações afetivas de apreço ou piedade pelo que adoece. Em alguns trabalhos foi postulado ampliar o tempo da consulta médica destinado à conversa com os doentes, como se isto, por si só, significasse uma relação mais humanizada no encontro clínico, sem que se caracterizasse a que finalidade responderia tal ampliação.

A discussão clara e direta sobre tais pré-juízos tem sido feita, embora difícil, mas tem se mostrado uma boa estratégia pedagógica para a valorização das Humanidades como conhecimento necessário à prática em medicina. Além disso, ofereceu aos dois anos seguintes de realização da disciplina importantes elementos de reorientação pedagógica, como a melhor delimitação de quais conceitos-chave mereciam outra forma de apresentação e maior discussão, o que se refletiu sobretudo nos módulos de Filosofia e História, que foram readequados e mostraram constituir o referencial humanístico de mais difícil e complexa apreensão, talvez por serem conhecimentos mais estranhos aos alunos.

Observamos que no transcurso dos três anos da disciplina, com a readequação processada, a noção de cuidado tem sido mais bem trabalhada pelos alunos, o que certamente também representa um progressivo aprimoramento docente.

O segundo momento de inflexão foi o exercício do último módulo, quando, por meio da aplicação de entrevista a pacientes, em busca de identificar e resgatar a pessoa do doente na doença, os alunos aplicaram, senão todos, muitos dos conteúdos conceituais e práticos trabalhados. O sucesso dessa última atividade demonstrou a inflexão, não só porque muitos alunos se aproximaram mais de seus professores, como houve maior discussão entre eles acerca de seus aprendizados e avaliações sobre a disciplina. Ao mesmo tempo, a grande adesão de quase todos a esse exercício e a boa avaliação que fizeram mostraram que muitos alunos, inicialmente menos atentos ou mais descrentes da importância da disciplina, desenvolveram maior interesse e bom desempenho.

Por fim, o terceiro ponto de inflexão notado diz respeito ao comportamento dos alunos frente à atividade de monitoria na disciplina e em fóruns oficiais de avaliação das disciplinas promovidos pela instituição. Quanto à monitoria, esta se iniciou com alunos da pós-graduação, mas tem recebido inscrições em volume crescente dos alunos egressos da graduação, o que tem demandado um processo de seleção dos mesmos. Esse novo interesse do corpo discente da escola médica chamou a atenção de muitos professores, o que foi explicitamente comentado em sessão da Congregação da faculdade, colegiado de instância máxima dos processos decisórios da instituição. Esse aspecto tem sido considerado por nós como um indicador de apreciação e atitude positivas diante da disciplina. Quanto ao comportamento dos alunos em fóruns oficiais, observou-se, desde o primeiro ano de realização da disciplina, que se quebrou uma espécie de consenso tácito acerca do baixo valor do conhecimento humanístico, podendo a disciplina ser vista como perda de tempo para o aluno. Os alunos têm assumido posições divergentes nos fóruns oficiais, denotando uma pluralidade de opiniões quanto à disciplina, bem como polarizando um número importante de alunos que a apreciam favoravelmente como ensino-aprendizagem em si e como conhecimento teórico e prático relevante para a formação em Medicina.

Ainda no tocante à avaliação do comportamento dos alunos durante o curso, e em perspectiva diversa, pode-se dizer que a avaliação feita por meio da observação das atividades por observador externo acrescentou elementos mais refinados para compreender o envolvimento dos alunos com uma disciplina tão peculiar como esta. Mesmo se sabendo que nem sempre esse é um recurso disponível, mostrou-se importante, ao menos para a implantação e o desenvolvimento inicial da disciplina.

O primeiro ponto que esse observador externo destacou se referia ao interesse dos alunos pelo que é apresentado em aula teórica. Identificou-se o modo diverso como os alunos se portavam nas aulas quanto a estarem sentados e quietos, olharem para o professor, se concentrarem no que é falado e debatido, e participarem com perguntas, quando motivados pelo professor ou mesmo espontaneamente. Observou-se que cerca da metade deles se portava positivamente frente a esses comportamentos, e tanto mais quanto mais se dispunham à frente da sala de aula, embora todos os professores assumissem a atitude de expor sua aula andando em diversas direções da sala e estimulando os alunos diretamente com perguntas. Já os alunos com comportamento diverso estavam, alguns, inquietos e lidando com telefones celulares, computadores, apostilas e outros materiais, e outros, adormecidos ou nitidamente distraídos e em seu próprio silêncio. Sem querer atribuir estritamente a tais comportamentos o interesse e a aprendizagem - pois também se observou que alguns desses alunos aparentemente ocupados em lidar com outro assunto que não o da aula se colocavam de modo apropriado quanto ao tema da aula e seu conteúdo em seus subgrupos de aula prática, 
que sempre se liga a cada uma das aulas expositivo-teóricas -, também se considerou que o interesse pelas aulas se conecta a outros elementos, como, por exemplo, com os desafios científicos representados pela disciplina e com desempenhos bons efetivamente conseguidos em avaliações na disciplina. Ambos são, portanto, aspectos a serem bastante considerados no desenvolvimento da disciplina, reforçando quer a realização de múltiplas formas avaliativas e de monitoramento do aluno, quer a importância da apresentação da complexidade conceitual de cada módulo e de suas contribuições práticas específicas para o cuidado.

Outro ponto destacado pelo observador externo foi uma disposição bastante tradicional na ocupação do espaço da sala: estar no terço anterior, mais à frente da sala, ou no terço mais posterior, no fundo da sala, além de se tratar de espaços intencionalmente buscados e de modo sistemático, também corresponde a condutas diversas. Os alunos que se sentaram mais à frente várias vezes se solidarizaram com o pedido de silêncio do professor e muitas vezes faziam tal pedido à classe espontaneamente. Em algumas ocasiões, os alunos "do fundão" tentaram provocar os demais com início de palmas ou demonstrações exageradas e descontextualizadas de apreço, para iniciarem manifestações coletivas, mais irônicas do que respeitosas, mas não foram seguidos pelo conjunto dos alunos, mostrando opiniões diversas na turma quanto à disciplina e a seu andamento.

No fim dessa trajetória toda, em que pesem as considerações quanto a avaliar resultados de aprendizagem por notas, os alunos conseguiram obter bom rendimento. Em relação ao desempenho na disciplina, considerando-se as notas obtidas nas atividades práticas, trabalhos de fim de módulo e prova final, mais de $80 \%$ dos alunos têm obtido aproveitamento com nota superior a 7,0. As maiores notas correspondem aos módulos de Socioantropologia e de psicodinâmica do encontro clínico, reforçando nossa percepção já expressa de que aspectos históricos e filosóficos, mesmo articulados à medicina e ao cuidado, são desafios de aprendizado maiores para esses alunos.

Na última aula, os alunos respondem a questionário de avaliação da disciplina com perguntas sobre todas as aulas, atividades práticas em grupo e externas, professores e a visão geral da disciplina. As respostas, fechadas, são dadas na escala Likert - péssimo, ruim, regular, bom e ótimo. Nas respostas obtidas nesses anos, tem aumentado a porcentagem dos que avaliam a disciplina como "ótima" ou "boa", inicialmente em torno de $68 \%$, o que consideramos uma perspectiva bastante animadora diante do que foi exposto em termos de recusa prévia do alunado às Humanidades.
Finalmente, quanto à proporção de respostas "ótima" ou "boa" para a atividade de trabalho final de cada módulo, observou-se uma preferência acentuada relativamente ao trabalho do módulo de psicodinâmica no encontro clínico, que tem apresentado sempre taxas em torno de $80 \%$ nessas referências. Esse trabalho é centrado na realização e discussão de entrevistas com os pacientes, o que representa o aspecto culminante da disciplina, em termos tanto do significado da prática clínica como núcleo da formação médica, quanto da possibilidade de concretização do uso prático das contribuições dos conhecimentos humanísticos. Esse momento é o que gera a síntese necessária para que o aluno possa compreender o sentido global das Humanidades, assim como o sentido humanístico da própria medicina. Isto permite que se compreenda, enfim, a contribuição efetiva das Humanidades para a graduação médica.

\section{CONSIDERAÇÕES FINAIS SOBRE A EXPERIÊNCIA}

Nas reuniões semanais dos docentes, os relatos do ocorrido em cada turma e das percepções acerca da didática e do comportamento dos alunos apontaram, desde o início, o trabalho em pequenos grupos como muito bom, seja na opinião dos docentes ou dos próprios alunos, como confidenciou um deles ao observador externo: "em pequeno grupo, o professor nos obriga a prestar atenção, o que é bem melhor".

O depoimento causou certo espanto ao revelar a necessidade de um dispositivo disciplinar "que vem de fora", do mais velho ou da maior autoridade (o professor), como se esses alunos ainda fossem bastante infantis e requeressem um controle externo e adicional. Igualmente causa espanto no que se refere ao contraste entre a autonomia e a liberdade de escolhas que os alunos em geral demandam, e que também a formação nas escolas médicas estimula, sobretudo nas atividades extracurriculares, como o aprendizado em ligas ou outras atividades de extensão, formalmente reconhecidas ou não pelas instituições de ensino.

Efetivamente, como indica a literatura ${ }^{4,18,19}$, na percepção dos professores e monitores, há maior aproveitamento e participação dos alunos nas atividades práticas em pequenos grupos do que nas aulas teóricas. Entretanto, essa diferença talvez signifique ou a natureza mais prática da atividade ou o fato de que se realize em pequeno grupo, pois, em uma turma de aproximadamente 90 alunos, tal qual nas aulas teóricas, o protagonismo do aluno fica prejudicado.

A ênfase em apontar as implicações práticas dos conteúdos conceituais de cada módulo - quer com exemplos nas aulas expositivas, quer pela vivência em aplicações concretas nas atividades de pequenos grupos - também se mostrou de 
grande importância para o aprendizado e o bom desenvolvimento da disciplina. De um lado, há o caráter pragmático da própria medicina, que deve se refletir na formação dos alunos. De outro, há que se ensinar o quanto todo pragmatismo é baseado em teorias e explicações, sendo as das Ciências Humanas e Sociais e da Filosofia boas contribuições nesta direção, ainda que o pragmatismo não seja uma característica própria dessas disciplinas, senão o ganho interdisciplinar das Humanidades em Medicina. Essa possibilidade foi em muito amparada pela eleição do "cuidado" como tema integrador dessa interdisciplinaridade e, na disciplina, concebido como núcleo da práxis em medicina e um elemento prático complexamente conceituado.

O fato de poder contar com mais de um ramo disciplinar do social e do humano foi benéfico para identificar, com a passagem de um a outro módulo, a distinta aproximação entre a medicina e os saberes eleitos para representar as "Humanidades" nesta disciplina, assim como a articulação entre eles. A eleição feita, é claro, não esgota todas as contribuições possíveis, como seria o caso, por exemplo, da Literatura, das Artes Plásticas ou do Cinema ${ }^{20}$.

Também em razão do grande número de conceitos novos trabalhados com os alunos, houve uma eleição de prioridade, com alguns deles sendo mais enfatizados que outros, tais como: êxito técnico e sucesso prático; permanências e rupturas históricas; illness e disease; empatia e comunicação.

Ao mesmo tempo, a circularidade de conteúdo teórico-conceitual foi alcançada graças à escolha acertada da sequência dos módulos, iniciando-se com os questionamentos filosóficos e concluindo-se com as questões das relações humanas presentes na prática em medicina.

Cada módulo dispôs de tempo bastante curto para se mostrar como campo específico das Humanidades, mas o conjunto restrito de conteúdos e conceitos-chave foi bem escolhido e bem selecionado quanto à relevância para representar as respectivas áreas das Ciências Humanas e Sociais e da Filosofia. Por ser o professor responsável por cada módulo um estudioso de cada ramo do conhecimento representado, ficou evidente a desenvoltura no trato dos temas, bem como na condução das discussões e exemplos práticos, o que mostrou que todos foram bem-sucedidos para passar da abstração teórico-conceitual a situações concretas particulares da realidade empírica equivalente. $\mathrm{O}$ recurso a exemplos da prática médica foi bastante explorado e bem acertado, assim como o recurso ao pluralismo dos meios didáticos, o que deu uma boa dinâmica do processo ensino-aprendizagem ao conjunto da disciplina. Foi fundamental também a presença de monitores - pessoas mais jovens e próximas dos alunos e também médicos - , per- mitindo maior fluidez na relação entre a teoria e a realidade concreta da prática médica, em razão das experiências já vividas, o que lhes forneceu, sem dúvida, um conjunto ampliado e apropriado de exemplos práticos para as reflexões mais abstratas da sala de aula.

Em termos dos meios didáticos, foi notória a preferência dos alunos por recursos visuais (filmes, vídeos). Estes se interessavam, primeiro, por informações veiculadas pelos vídeos/filmes; em segundo lugar, por exemplos práticos de casos clínicos ou situações profissionais; e em terceiro, por conceitos bem formulados e bem apresentados.

Por fim, em termos do sentido geral dessa experiência para os docentes participantes, este foi, sem dúvida, o desafio dessa construção interdisciplinar. Dela se pode afirmar que, se a interdisciplinaridade implica a arte de respeitar o específico e produzir interações geradoras do conhecimento integrado, nesta disciplina, o saber interdisciplinar sobre o cuidado ficou bem constituído. Em complemento, as trocas intersubjetivas também permitiram que cada "especialista" em um ramo das Humanidades captasse o todo do cuidado em medicina, permeando seu particular conhecimento dos demais, enriquecendo sua experiência de cientista e professor.

\section{CONCLUSÃO}

A formação humanística do aluno na graduação médica requer estratégias educacionais e ambientais, entre as quais a inserção curricular de disciplinas de Humanidades. Apresentamos a experiência de desenvolvimento de uma disciplina de Humanidades Médicas, estruturada em quatro módulos alinhados pelo conceito e prática do Cuidado em Saúde: Filosofia, História, Socioantropologia e Psicodinâmica do Encontro Clínico. Os módulos foram coordenados por professores especialistas, que adotaram diferentes metodologias didático-pedagógicas para seu desenvolvimento. O desenho da disciplina mostrou-se adequado aos objetivos educacionais propostos, e sua boa avaliação e aceitação por alunos e professores reforçam a importância de aprimorar o ensino de Humanidades na escola médica.

\section{AGRADECIMENTOS}

Os autores agradecem a Ademir Lopes Júnior, Mariana Arantes Nasser e Cássia Regina Suzuki por suas colaborações.

\section{REFERÊNCIAS}

1. Brody H. Defining the Medical Humanities: three conceptions and three narratives. J Med Humanit. 2011;32(1):1-7. DOI:10.1007/s10912-009-9094-4.

2. Mosley P. Role of the Humanities in the Education of Health Professionals. Med Teach. 1989;11(1):99-101. 
3. Rios IC, Schraiber LB. Uma relação delicada: estudo do encontro professor-aluno. Interface Comun. Saúde Educ. 2010;15(36):39-52.

4. Rios IC. Subjetividade contemporânea na educação médica: a formação humanística em medicina. São Paulo; 2010. Doutorado [Tese] - Faculdade de Medicina da Universidade de São Paulo.

5. Rider EA, Keefer $\mathrm{CH}$. Communication skills competencies: definitions and a teaching toolbox. Med Educ. 2006;40(7):624-9. DOI:10.1111/j.1365-2929.2006.02500.x

6. Caldicott CV, Danis M. Medical ethics contributes to clinical management: teaching medical students to engage patients as moral agents. Med Educ. 2009;43(3):283-9. DOI: doi: 10.1111/j.1365-2923.2008.03277.x.

7. Cassel EJ. Unanswered questions: Bioethics and human relationships. The Hasting Center Report. 2007;37(5):20-3.

8. Halperin EC. Preserving the humanities in medical education. Med Teach. 2010;32(1):76-9. DOI: 10.3109/01421590903390585.

9. Gülpinar M, Akman M, User I. A course, 'The Human in Medicine', as an example of a preclinical medical humanities program: a summary of 7 years. Med Teach. 2009;31(10): e469-76. DOI: 10.3109/01421590802638014.

10. Brasil. Ministério da Educação. Conselho Nacional de Educação. Câmara de Educação Superior. Resolução CNE/ CES nº 4 de 7 de novembro de 2001. Institui diretrizes curriculares nacionais do curso de graduação em Medicina. Diário Oficial da União. Brasília, nov. 2001; Seção 1, p.38.

11. Brasil. Gestão do Trabalho e da Educação na Saúde. Programa Nacional de Reorientação da Formação Profissional em Saúde (Pró-Saúde). Brasília, 2011. [acesso em 20 maio 2013]. Disponível em: http:/ / portal.saude.gov.br/portal/ saude/profissional/visualizar_texto.cfm?idtxt=26639.

12. Brasil. Ministério da Saúde. Portal da Saúde. Gestão do Trabalho e da Educação na Saúde. Programa de Educação pelo Trabalho para a Saúde - PET [online]. Brasília; 2011 [acesso em 20 maio 2013]. Disponível em: http://portal. saude.gov.br/portal/saude/profissional/visualizar_texto.cfm?idtxt $=35306$.

13. Universidade de São Paulo .Faculdade de Medicina. Conferência de Busca do Futuro: FMUSP 2020 [online]. São Paulo; 2010 [acesso em 20 maio 2013]. Disponível em: http:/ /www.fm.usp.br/fmusp2020/
14. Harden RM. Ten questions to ask when planning a course or curriculum. Med Educ. 1986;20(4):356-65. DOI: 10.1111/ j.1365-2923.1986.tb01379.x

15. Ayres JRCM. Cuidado: trabalho e interação nas práticas de saúde. Rio de Janeiro: Cepesc-IMS/UERJ/Abrasco; 2011.

16. Marcondes E; Gonçalves EL. Educação Médica. São Paulo: Sarvier;1999.

17. Savulescu J, Crisp R, Fulford KW, Hope T. Evaluating ethics competence in medical education. J Med Ethics. 1999;25(5)367-74. DOI: 10.1136/jme.25.5.367

18. Van Dalen J, Bartholomeus P, Kerkhofs E, Lulofs R, Van Thiel J, Rethans JJ, et al. Teaching and assessing communication skills in Maastricht: the first twenty years. Med Teach. 2001;23(3):245-51. DOI: 10.1080/01421590120042991

19. Turini B, Martins Neto D, Tavares MS, Nunes SOB, Silva VLM, Thomson Z. Comunicação no ensino médico: estruturação, experiência e desafios em novos currículos médicos. Rev Bras Educ Med. 2008; 32(2):264-70. DOI:10.1590/ S0100-55022008000200015

20. Pereira RTMC. O ensino da medicina através das humanidades médicas: análise do filme "and the band played on" e seu uso em atividades de ensino/aprendizagem em educação médica. São Paulo; 2004. Doutorado [Tese] - Universidade de São Paulo.

\section{CONTRIBUIÇÃO DOS AUTORES}

José Ricardo Ayres, Izabel Rios e Lilia Schraiber, trabalharam na concepção do artigo, e junto com Marcia Couto e André Mota, redigiram o artigo. A revisão final coube aos três primeiros autores.

\section{CONFLITO DE INTERESSES}

Declarou não haver.

\section{ENDEREÇO PARA CORRESPONDÊNCIA}

José Ricardo C. M. Ayres

Faculdade de Medicina da USP — Departamento

de Medicina Preventiva

Av. Dr. Arnaldo, 455 - sala 2213

Cerqueira Cesar — São Paulo

CEP 01246-903 - SP

E-mail: jrcayres@usp.br 